\title{
Roots of Cooperation: Can Root Graft Networks Benefit Trees Under Stress?
}

\section{Alejandra Vovides ( $\square$ Alejandra.Vovides@glasgow.ac.uk)}

University of Glasgow

\section{Marie-Christin Wimmler}

Technische Universität Dresden

\section{Falk Schrewe}

Technische Universität Dresden

\section{Thorsten Balke}

University of Glasgow https://orcid.org/0000-0001-7733-5069

\section{Martin Zwanzig}

TU Dresden https://orcid.org/0000-0003-1866-6743

\section{Cyril Piou}

CIRAD, UMR CBGP, INRAE, Institut Agro, IRD, Univ Montpellier

\section{Etienne Delay}

CIRAD, UR, GREEN

Jorge López-Portillo

INECOL A.C.

\section{Uta Berger}

Technische Universitaet Dresden

\section{Article}

\section{Keywords:}

Posted Date: December 1st, 2020

DOI: https://doi.org/10.21203/rs.3.rs-112267/v1

License: (c) (i) This work is licensed under a Creative Commons Attribution 4.0 International License.

Read Full License

Version of Record: A version of this preprint was published at Communications Biology on May 5th, 2021. See the published version at https://doi.org/10.1038/s42003-021-02044-x. 
Roots of cooperation: can root graft networks benefit trees under stress?

Alejandra G. Vovides ${ }^{1 *}$, Marie-Christin Wimmler ${ }^{2}$, Falk Schrewe ${ }^{2}$, Thorsten Balke ${ }^{1}$, Martin Zwanzig $^{2}$, Cyril Piou ${ }^{3}$, Etienne Delay ${ }^{4}$, Jorge López-Portillo ${ }^{5}$, Uta Berger ${ }^{2}$

${ }^{1}$ School of Geographical and Earth Sciences, University of Glasgow, Scotland, UK

${ }^{2}$ Institute of Forest Growth and Forest Computer Sciences, Technische Universität Dresden, Germany

${ }^{3}$ CIRAD, UMR CBGP, INRAE, Institut Agro, IRD, Univ Montpellier, F-34398 Montpellier, France

${ }^{4}$ CIRAD, UR GREEN, F-34398 Montpellier, France.

${ }^{5}$ Functional Ecology Network, Instituto de Ecología A.C., Mexico

\section{Word counts}

202 (Summary paragraph)

2,030 (Main)

360 (Figure legends)

1,601 (Methods)

4,235 (Summary + Main + Figure legends + author contributions (42)) 


\section{Summary}

The occurrence of natural root grafts, the functional union of roots of the same or different trees ${ }^{1-3}$, is common and shared across tree species ${ }^{2}$. However, their significance for forest ecology remains little understood. While early research suggested negative effects of root grafting (i.e. increases the risk of pathogen transmission) ${ }^{4,5}$, recent evidence supports the hypothesis that it is an adaptive strategy that reduces stress $^{6-8}$ by facilitating resource exchange ${ }^{9,10}$. Here by analysing mangrove root graft networks, we show evidence of cooperation-associated benefits of root grafting. Grafted trees were found to dominate the upper canopy of the forest, and as the probability of grafting and the frequency of grafted groups increased with a higher environmental stress, the mean group size (number of trees within grafted groups) decreased. While root networks could form randomly (i.e. trees do not actively 'choose' neighbours to graft to $)^{11,12}$, the increased frequency and reduced group sizes of connected trees in higher-stress environments point to the existence of underlying mechanisms that regulate 'optimal size' group selection related to resource use within cooperating groups $^{8,13,14}$. This work calls for further studies to better understand tree interactions (i.e. network hydraulic redistribution $)^{15}$ and their consequences for individual tree and forest stand resilience and water-use efficiency. 


\section{MAIN}

Natural root grafts, the physical connection of two roots belonging to different trees or a single individual tree, have been known about for more than 100 years $^{3}$ and are recognised in almost 200 tree species ${ }^{2,16}$. However, until the last decade, we had had little information about their ecological implications for tree interactions and forest stand dynamics. Between the 1950s and the 1990s, they were mainly regarded as a phenomenon of random occurrence or a threat to forest stands due to their role as vectors of pathogen transmission in forest stands ${ }^{5}$ and the only long-term accepted consequence of grafting as a positive trait was increased mechanical stability $2,16,17$. Now, the common perception of forest dynamics being ruled only by competition and survival of the fittest is being challenged by the discovery of mycorrhizal networks and the re-evaluation of root-grafts as critical vectors of positive interactions amongst trees ${ }^{18-23}$.

Root grafts can be either non-functional or functional (cambia and vascular tissues are fused $^{2}$ ). Non-functional grafts confer higher mechanical stability through shared anchoring systems ${ }^{17}$, which is particularly relevant for coastal wetland forests with shallow root systems ${ }^{16,24}$ due to anoxic sediments, and exposure to strong winds ${ }^{25}$. Functional grafts can additionally facilitate resource exchange ${ }^{21}$ and promote growth ${ }^{7}$ by mitigating the adverse effects of defoliation and budworm outbreaks ${ }^{10,26}$ and increasing the concentration of carbohydrates in shaded trees ${ }^{21}$. By enabling the exchange of water, carbon, and mineral nutrients, severed trees can be kept alive through the support of grafted neighbours ${ }^{27}$. Moreover, modelling approaches suggest that natural root grafts could explain short-range positive interactions that lead to large-scale fractal patterns in tree yield ${ }^{28}$ that seem to predestine natural root grafting as a cooperative trait. However, our current knowledge is mainly based on the study of grafted pairs of trees, and spatially explicit field investigations 
are limited to small plots in terrestrial forests ${ }^{3,6,22,29}$, while the functional ecology of root grafts in wetland forests, and the effect of environmental stress on network topology remains unexplored.

Until now, the study of root grafts has required the extensive excavation of root systems ${ }^{5-}$ $7,29,30$ and, often, decades to gather quality information ${ }^{7}$. The inclusion of environmental gradients to understand positive plant interactions and their ecological implications for community dynamics ${ }^{31,32}$ is therefore very limited. However, mangrove forests, with their distinct environmental/elevational gradients ${ }^{32}$ and traceable shallow root system with pneumatophores (e.g., the pencil-like emerging roots of Avicennia spp.), offer an ideal model system to study the ecological role of root graft networks. Avicennia germinans L. dominates forests on hypersaline mudflats with limited tree diversity, and strong salinity gradients offer particularly satisfactory conditions to study physiological responses ${ }^{33}$, tree architecture, and tree interactions ${ }^{25,34,35}$. These mangrove specificities provide ideal conditions to investigate in the field whether root grafting can benefit trees growing under environmental stress through an analysis of individual tree attributes and spatial root graft network structures.

\section{Drivers of root grafting and implications for tree size}

To understand the main drivers and consequences of natural root grafting in an A. germinans dominated forest, we focused on a seasonally hypersaline mangrove forest bordering the coast of the Gulf of Mexico (Fig. 1A). A steel rod root detection method developed to measure root length with minimal excavation ${ }^{36}$ was modified to identify and map root graft networks in eight $900 \mathrm{~m}^{2}$ forest stands (Fig.1B). We further related root graft frequency to biotic and abiotic variables, such as stem diameter, stand density and porewater salinity (see methods section). We also explored the height-diameter relationship of grafted and non- 
grafted trees with different neighbourhood asymmetries (i.e., competition pressure by neighbours; see Supplementary Information) and the relationships between the related network group attributes of group size and frequency to stand density and salinity.

Porewater salinity ranged between $39.7 \pm 1.5$ (mean $\pm \mathrm{SE}$ ) and $58 \pm 0.8 \mathrm{ppt} ;$ A. germinans stand densities ranged between 300 and 900 trees ha $^{-1}$ and root graft frequency ranged between $34 \%$ and $70 \%$, increasing with salinity. $77 \%$ of the top-height trees were grafted. Top-height trees, defined as the $20 \%$ biggest trees in a stand (as per stem diameter, see methods section), are considered to have exploited resources to their maximum ability, and thus reflect the potential productive capacity of a stand ${ }^{37}$. The high frequency of grafting in the most dominant trees suggests that a shared root system provides essential advantages to the forest, either by optimizing resource exploitation or by increasing mechanical stability and windthrow resistance.

In line with previous studies ${ }^{6,38,39}$, the probability of grafting increased with increasing tree stem diameter $(\mathrm{p}<0.0001$; Fig. $2 \mathrm{~A})$. With the addition of salt stress, however, the contribution of stem diameter to grafting probability decreased for stem diameters $>20 \mathrm{~cm}$ (Fig. 2A; Extended Data Table 1). In upland forests, higher stand densities contribute to increased grafting probability because of reduced distances between neighbouring trees ${ }^{38}$. In our study, however, stand density reduced grafting probabilities. This could be due to higher resource limitations within saline environments. First, closer neighbours result in greater competition $^{37}$, while high salt stress additionally reduces resource availability and limits growth rates ${ }^{33,40}$, leading to smaller stem diameters within the stand. Independently, stand density and salinity lead to smaller stem diameters, thus reducing the probability of grafting (Fig. 2A). However, trees with smaller stem diameters have a higher probability of grafting at 
high salinity and stand density sites (Extended Data Table 1). The highest proportion of grafting was recorded for plots with the highest stand densities and salinities (Extended Data Fig. 1), suggesting that salt stress has direct control over root grafting.

The generalised additive mixed model that was used to explore the effect of grafting on tree size, demonstrated that grafted trees are generally taller than non-grafted trees $(p<0.01$, Fig. 2B). The model $\left(\mathrm{R}^{2}=0.78\right.$, explaining $85 \%$ of de deviance) showed that neighbourhood asymmetry did not influence tree height of grafted trees $(p=0.46$ and $p=0.25$, for grafted and non-grafted trees, respectively) (Extended Data Fig. 3A,B), but they have a more linear relationship between stem diameter and height ( $\mathrm{p}<0.001$; Fig. 2B; Extended Data Fig. 3C) contrasted with the markedly reduced rate of height increase for non-grafted trees with stem diameters between 10 and $30 \mathrm{~cm}(\mathrm{p}<0.001$; Fig. 2B; Extended Data Fig. 3D). Suggesting grafts provide a benefit to trees, which could be due to either a potential increased growth rate $^{6,21}$ if grafts are fully functional, or due to increased mechanical stability related to an extended area for anchorage ${ }^{17}$.

\section{The height to stem ratio (so called slenderness) is an allometric trait ${ }^{41}$ that determines} mechanical stability. Very slender trees are more vulnerable to windthrow, while low slenderness coefficients increase wind resistance ${ }^{42}$. Slenderness varies throughout tree development; younger trees invest in height growth before girth as a result of competition for light, which increases their risk of mechanical failure ${ }^{42}$. As they reach the canopy, more resources are invested in stem girth, conferring higher mechanical stability and resistance to windthrow ${ }^{4-43}$. Further assessing changes in slenderness along the range of stem diameters (Fig. 2C), we found a significant increase in slenderness for non-grafted trees that are subject to higher competition pressure ( $\mathrm{p}=0.02$, Extended Data Table 2). However, we also detected a 
significant, but weak negative interaction between stem diameter, grafting condition and neighbourhood asymmetry $(\mathrm{p}=0.01$, Extended Data Table 2$)$. As non-grafted trees increase in diameter, their slenderness decreases more rapidly than it does for grafted trees (Fig. 2C). This points towards potentially increased mechanical stability for dominant grafted trees with greater wind exposure than their neighbours ${ }^{42}$. This finding is consistent with the higher slenderness reported for grafted hybrid poplar clones ${ }^{22}$.

\section{Network formation}

Trees can benefit from functional root grafts through the increase of foraging area via communal root systems ${ }^{1,2}$.Root networks could also mitigate salinity-induced physiological drought through water redistribution between stems ${ }^{26,27}$. Further, shared carbohydrate pools could improve tree responses to both abiotic and biotic stress ${ }^{19,20}$. These factors likely contribute to the dominance of the forest canopy by grafted individuals. We challenged this hypothesis through the analyses of network topologies along the salt-stress gradient, where the lack of resource exchange would result in random network formation patterns, and similar network topologies along the stress gradient.

In forests, the location of individual trees is fixed after their establishment, and network formation is determined by physical, genetic and size proximity ${ }^{38}$, limiting any preferential attachment processes. Although the root networks in our study might fit a scale-free powerlaw distribution $(\mathrm{p}=0.21$; Fig. $3 \mathrm{~A})$, that is, they might possess patterns of continuous growth and preferential attachment ${ }^{11}$, we found no significant power of determination to reject random network formation when comparing the power-law distribution to log-normal ( $\mathrm{p}=$ 0.99), Poisson $(p=0.93)$ or exponential distributions $(p=0.99$; Fig. 3A). In this context, grafting could be a random process ${ }^{2,6}$; however, the distribution of the node degree (number 
of trees connected to a given tree via root grafts), the group frequency distribution and group size along the stand-density gradient (Fig. 3B, C) point to underlying mechanisms that select for optimal group size in cooperative groups ${ }^{11}$.

Most of the grafted trees were connected to one (61\%) or two (29\%) individuals, while connections to four partners were rare $(1 \%)$. Hence, the node degree's relative frequency is smaller with increasing node degree (Fig. 3A). Additionally, the average node degree is negatively correlated to stand density $\left(\mathrm{R}^{2}=0.40 ; \mathrm{p}=0.05\right.$; Fig. $\left.3 \mathrm{~B}\right)$ and the frequency of grafted trees $\left(\mathrm{R}^{2}=0.93 ; \mathrm{p}<0.001 ;\right.$ Fig. $\left.3 \mathrm{~B}\right)$. Consequently, the average node degree was highest in the plot with the lowest stand density and highest grafting frequency (Fig. 3B). Likewise, as $A$. germinans stand density increased, the average number of trees forming groups became smaller $\left(\mathrm{R}^{2}=0.62 ; \mathrm{p}=0.01\right.$; Fig. $\left.3 \mathrm{C}\right)$, whereas the frequency of groups increased $\left(\mathrm{R}^{2}=0.73 ; \mathrm{p}<0.01 ;\right.$ Fig. $\left.3 \mathrm{C}\right)$. This is in line with network theory findings of cooperative interactions increasing with environmental stress ${ }^{14,44}$. Such interactions, however, do not come without costs. It costs each cooperating individual to provide a benefit to its neighbours, and to be selected as an adaptive trait within a population, the net gain of the cooperative trait should be greater than its $\operatorname{cost}^{44}$.

There is evidence that in unweighted networks, selection favours cooperation when the benefit-cost ratio $\left(\frac{b}{c}\right)$ exceeds the average number of neighbours $(k)$ (i.e., node degree): $\left(\frac{b}{c}\right)>k$. Thus, most cooperative groups tend to have few members ${ }^{14,44,45}$ and higher probabilities of direct reciprocity (i.e., pairwise ties) ${ }^{45}$. The average node degree in the mangrove root networks we studied was smaller at sites with high salinity and high stand density compared with low salinity and medium stand density (Fig. 3B). However, stand densities were similar in low-and high-stress environments. As the cost of cooperation 
increases under stressful conditions ${ }^{14}$, assuming that a tree receives constant benefit from its cooperating neighbours, the critical $\left(\frac{b}{c}\right)$ ratio decreases with increasing stress. Thus, larger tree groups are not selected under situations of limited resource availability. Most of the grafted mangrove groups (73\%) consisted of only two or three members. However, of the groups that included more than two trees, $72 \%$ had no more than the minimum required number of connections for a cooperative system (each individual had at least one connection for cooperation within its group members). This supports the hypotheses that functional root grafts can only be maintained if there is a long-term payoff for all group members and underlying mechanisms selected for optimal group size in root networks.

These network topologies provide preliminary evidence that root networks are the result of cooperation, enabling small groups to perform better under stress ${ }^{14,44}$. Our study suggests that spatial resource limitation affects the network structure by modulating the number of interacting individuals and, potentially, the magnitude of their interactions ${ }^{12}$. Increasing numbers of studies on the ecological implications of network formation via root grafts (i.e., the implications of root grafting for water-use efficiency, hydraulic redistribution and nutrient exchange) will contribute to a greater understanding of the trade-off between positive and negative interactions. That is, positive interactions confer ecological advantages that overcome harsh environmental conditions, although the cost could include a higher risk of pathogen transmission. More broadly, our findings widen the path opened by Kropotkin's (1902) Mutual Aid: A Factor of Evolution ${ }^{13}$, which was largely forgotten during the 20th century.

\section{References}

1. Graham, B. F. Transfer of dye through natural root grafts of Pinus strobus L. Ecology 41, 56-64 (1960). 
2. Graham, B. F. \& Bormann, F. H. Natural root grafts. Bot. Rev. 32, 255-292 (1966).

3. Yli-Vakkuri, P. Studies on physical root connections between the trees in Scots pine stands in Finland. Acta For. Fenn. 60, 5-117 (1953).

4. Baric, S., Kerschbamer, C., Vigl, J. \& Dalla Via, J. Translocation of apple proliferation phytoplasma via natural root grafts - A case study. Eur. J. Plant Pathol. 121, 207-211 (2008).

5. Epstein, A. Root graft transmission of tree pathogens. Annu. Rev. phitopathology 196, 181-192 (1978).

6. Tarroux, E. \& DesRochers, A. Frequency of root grafting in naturally and artificially regenerated stands of Pinus banksiana: influence of site characteristics. Can. J. For. Res. 40, 861-871 (2010).

7. Tarroux, E. \& DesRochers, A. Effect of natural root grafting on growth response of jack pine (Pinus banksiana; Pinaceae). Am. J. Bot. 98, 967-74 (2011).

8. McIntire, E. J. B. \& Fajardo, A. Facilitation within species: a possible origin of groupselected superorganisms. Am. Nat. 178, 88-97 (2011).

9. Baret, M. \& DesRochers, A. Root connections can trigger physiological responses to defoliation in nondefoliated aspen suckers. Botany 89, 753-761 (2011).

10. Salomón, R. L., Tarroux, E. \& DesRochers, A. Natural root grafting in Picea mariana to cope with spruce budworm outbreaks. Can. J. For. Res. 46, 1059-1066 (2016).

11. Barabási, A.-L. \& Réka, A. Emergence of scaling in random networks. Science (80-. ). 286, 509-513 (1999).

12. Gao, J., Barzel, B. \& Barabási, A.-L. Universal resilience patterns in complex networks. Nature 536, 238-238 (2016).

13. Kropotkin, P. Mutual Aid: a factor of evolution. (1902). doi:10.2307/2140787

14. Delay, E. \& Piou, C. Mutual aid: when does resource scarcity favour group 
cooperation? Ecol. Complex. 40, 100790 (2019).

15. Nadezhdina, N., Nadezhdin, V. \& Prax, A. Vertical and horizontal water redistribution in Norway spruce (Picea abies) roots in the Moravian Upland. Tree Physiol. 1277$1288(2006)$

16. Keeley, J. Population variation in root grafting and a hypothesys. Oikos 52, 364-366 (1988).

17. Stokes, A. et al. Mechanical resistance of different tree species to rockfall in the French Alps. Plant Soil 278, 107-117 (2005).

18. Egerton-Warburton, L. M., Querejeta, J. I. \& Allen, M. F. Common mycorrhizal networks provide a potential pathway for the transfer of hydraulically lifted water between plants. J. Exp. Bot. 58, 1473-1483 (2007).

19. Deslippe, J. R., Hartmann, M., Grayston, S. J., Simard, S. W. \& Mohn, W. W. Stable isotope probing implicates a species of Cortinarius in carbon transfer through ectomycorrhizal fungal mycelial networks in Arctic tundra. New Phytol. 210, 383-390 (2016).

20. Klein, T., Siegwolf, R. T. \& Kröner, C. Belowground carbon trade among tall trees in a temperate forest. Science 352, 342-344 (2016).

21. Fraser, E. C., Lieffers, V. J. \& Landhäusser, S. M. Carbohydrate transfer through root grafts to support shaded trees. Tree Physiol. 26, 1019-23 (2006).

22. Gaspard, D. T. \& DesRochers, A. Natural root grafting in hybrid poplar clones. Trees Struct. Funct. 34, 881-890 (2020).

23. Quer, E., Baldy, V. \& DesRochers, A. Ecological drivers of root grafting in balsam fir natural stands. For. Ecol. Manage. 475, 118388 (2020).

24. McKee, K. L. Root proliferation in decaying roots and old root channels: A nutrient conservation mechanism in oligotrophic mangrove forests? J. Ecol. 89, 876-887 
(2001).

25. Vovides, A. G. et al. Change in drivers of mangrove crown displacement along a salinity stress gradient. Funct. Ecol. 32, 2753-2765 (2018).

26. Adonsou, K. E., Drobyshev, I., DesRochers, A. \& Tremblay, F. Root connections affect radial growth of balsam poplar trees. Trees - Struct. Funct. 30, 1775-1783 (2016).

27. Adonsou, K. E., DesRochers, A. \& Tremblay, F. Physiological integration of connected balsam poplar ramets. Tree Physiol. 36, 797-806 (2016).

28. Noble, A. E., Rosenstock, T. S., Brown, P. H., Machta, J. \& Hastings, A. Spatial patterns of tree yield explained by endogenous forces through a correspondence between the Ising model and ecology. Proc. Natl. Acad. Sci. 115, 1825-1830 (2018).

29. Jelínková, H., Tremblay, F. \& DesRochers, A. Molecular and dendrochronological analysis of natural root grafting in Populus tremuloides (Salicaceae). Am. J. Bot. 96, $1500-1505$ (2009).

30. Bormann, F. H. The structure, function, and ecological significance of root grafts in Pinus strobus L. Ecol. Monogr. 36, 1-26 (1966).

31. Callaway, R. M. et al. Positive interactions among alpine plants increase with stress. Nature 417, 844-848 (2002).

32. Huxham, M., Berger, U., Skov, M. W. \& Sousa, W. P. Kropotkin’s Garden: facilitation in mangrove ecosystems. (2019).

33. Ball, M. C. \& Farquhar, G. D. Photosynthetic and stomatal responses of the grey mangrove, Avicennia marina, to transient salinity consitions. Plant Physiol. 74, 7-11 (1984).

34. Lin, Y., Berger, U., Grimm, V., Huth, F. \& Weiner, J. Plant interactions alter the predictions of metabolic scaling theory. PLoS One 8, e57612 (2013). 
35. Osland, M. J., Day, R. H., Larriviere, J. C. \& From, A. S. Aboveground allometric models for freeze-affected black mangroves (Avicennia germinans): equations for a climate sensitive mangrove-marsh ecotone. PlosOne 9, e99604 (2014).

36. Vovides, A. G., Marín-Castro, B., Barradas, G., Berger, U. \& López-Portillo, J. A simple and cost-effective method for cable root detection and extension measurement in estuary wetland forests. Estuar. Coast. Shelf Sci. 183, 117-122 (2016).

37. West, P. W. Tree and Forest Measurement. (Springer-Verlag, 2009).

38. Fraser, E. C., Lieffers, V. J. \& Landhäusser, S. M. Age, stand density, and tree size as factors in root and basal grafting of lodgepole pine. Can. J. Bot. 83, 983-988 (2005).

39. Bormann, F. H. \& Graham, B. F. The occurrence of natural root grafting in eastern White pine, Pinus strobus L., and Its ecological implications. Ecology 40, 677-691 (1959).

40. Westoby, M. The place of the self-thinning rule in population dynamics. Am. Nat. 118, 581-587 (2008).

41. Wang, Y., Titus, S. J. \& LeMay, V. M. Relationships between tree slenderness coefficients and tree or stand characteristics for major species in boreal mixedwood forests. Can. J. For. Res. 28, 1171-1183 (1998).

42. MacFarlane, D. W. \& Kane, B. Neighbour effects on tree architecture: Functional trade-offs balancing crown competitiveness with wind resistance. Funct. Ecol. 31, $1624-1636(2017)$.

43. Brüchert, F. \& Gardiner, B. The effect of wind exposure on the tree aerial architecture and biomechanics of Sitka spruce (Picea sitchensis, Pinaceae). Am. J. Bot. 93, 1512$1521(2006)$.

44. Allen, B. et al. Evolutionary dynamics on any population structure. Nature 544, 227 230 (2017). 
45. Ohtsuki, H., Hauert, C., Lieberman, E. \& Nowak, M. A. A simple rule for the evolution of cooperation on graphs and social networks. Nature 441, 502-505 (2006).

\section{Acknowledgements}

This paper is dedicated to the memory of Adán Vez Lira, a man of wit and faith, who drew the path of conservation and sustainability on the coast of Veracruz and died on the 8th of April 2020 defending nature and the well-being of his community, and our extended family of La Mancha en Movimiento. Our work would not be possible without your conservation efforts, drive and smiles. This research was financed by the Volkswagen Foundation (Volkswagen Stiftung, Project No. 94 844) and partially financed by the MOMENTS project (NERC, UK grant No. NE/P014127/1). Support by the Association of Friends and Sponsors of TU-Dresden e.V. and INECOL was provided to F.S. (GFF, grant No. 61/2017 and INECOL, project No. 00016, respectively). Editing support was provided by the Research and Innovation services of the University of Glasgow.

\section{Author contributions}

Project idea and development of the experimental design (A.V., J.L.P., F.S. and U.B.). Fieldwork and data collection (A.V., F.S. and J.L.P). Data analysis (A.V., M.C.W., M.Z., T.B, E.D. and C.P). Writing and editing the manuscript (A.V., M.C.W., T.B., J.L.P., F.S, C.P, E.D. and U.B.).

Competing Interests declaration. The authors declare no competing interests.

Correspondence and request for materials. Should be addressed to A.V. 


\section{Figure legends}

Figure 1. A Study site located on the central coast of the Gulf of Mexico (left). La Mancha lagoon (see insert), surrounded by mangrove vegetation, contains 13 permanent plots (red and blue points) used for vegetation monitoring. Root grafts were mapped within eight of these stands (red points). B Root-grafted tree network maps representative of sites with low, medium and high salinity and the stand density (left, middle and right, respectively). The yellow dots represent stem positions; the coloured circles (green, peach and blue) are the tree crowns of black mangrove (Avicennia germinans), red mangrove (Rhizophora mangle) and white mangrove (Laguncularia racemosa), respectively; and the black lines represent graft connections.
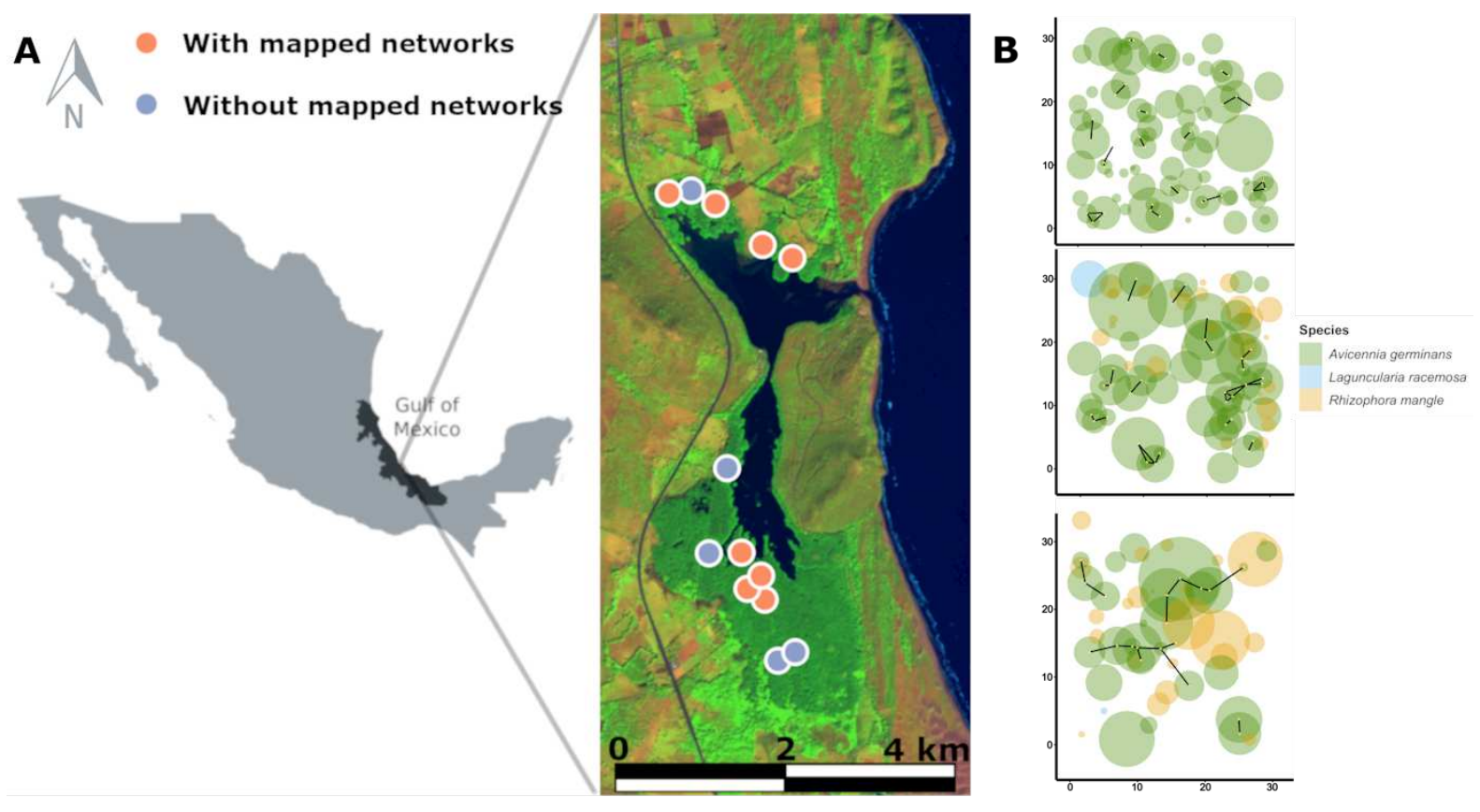
Figure 2. A Logistic regression testing of the main drivers of root grafting. Although, for all cases, the probability of grafting increases with increasing stem diameter, at higher salinity stress and total density values, trees graft at smaller stem diameters, and the probability curve rises earlier and is steeper. B Non-linear relationship between stem diameter and tree height showcasing stem diameter-height allometric curves that are steeper for grafted (purple) trees compared with non-grafted (green) trees. There is a predominance of grafted trees with stem diameters $>20 \mathrm{~cm}$, whereas the tallest trees are either grafted or have smaller values of neighbourhood asymmetry (circle size). C Sharp decrease in slenderness coefficient with increasing stem diameter for non-grafted trees, at higher stem diameters grafted trees are more slender
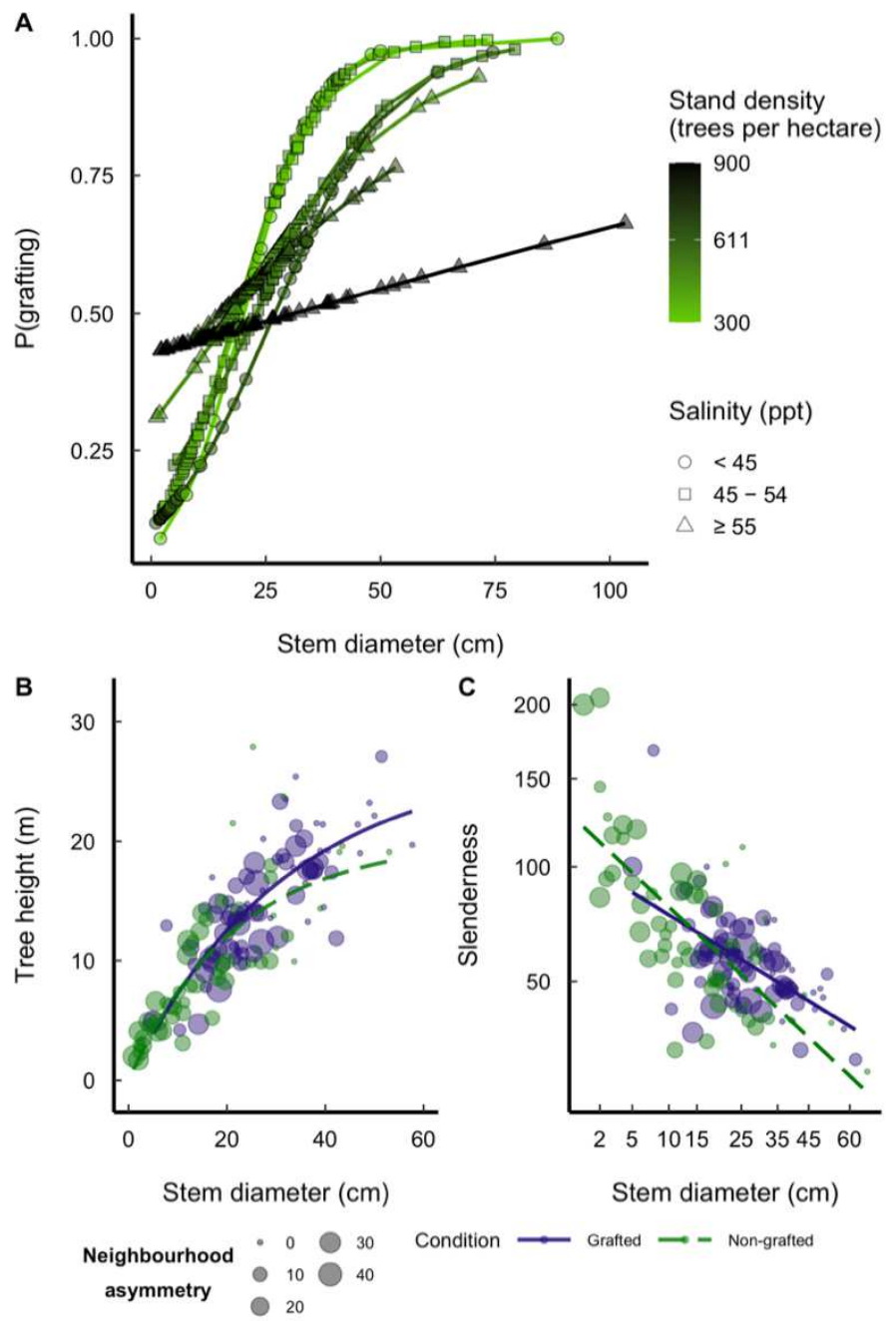
Figure 3. A Comparison of log-transformed cumulative distribution functions (CDF). The number of direct connections for a given tree (node degree) shows that although the root graft networks might fit a scale-free power-law distribution, Poisson, log-normal and exponential distributions cannot be discarded. B Linear regression showing a reduction on the average node degree of the networks along the $A$. germinans stand-density gradient and grafting frequency (\%). Shape and colour depict the salinity range of the plots (purple circles $>45 \mathrm{ppt}$, green squares $45-55 \mathrm{ppt}$ and brown triangles $>55 \mathrm{ppt}$ ) and the size of each shape indicates the stand's grafting frequency. C Linear regression showing an increasing number of groups of grafted trees per hectare with significant reduction in mean group size.
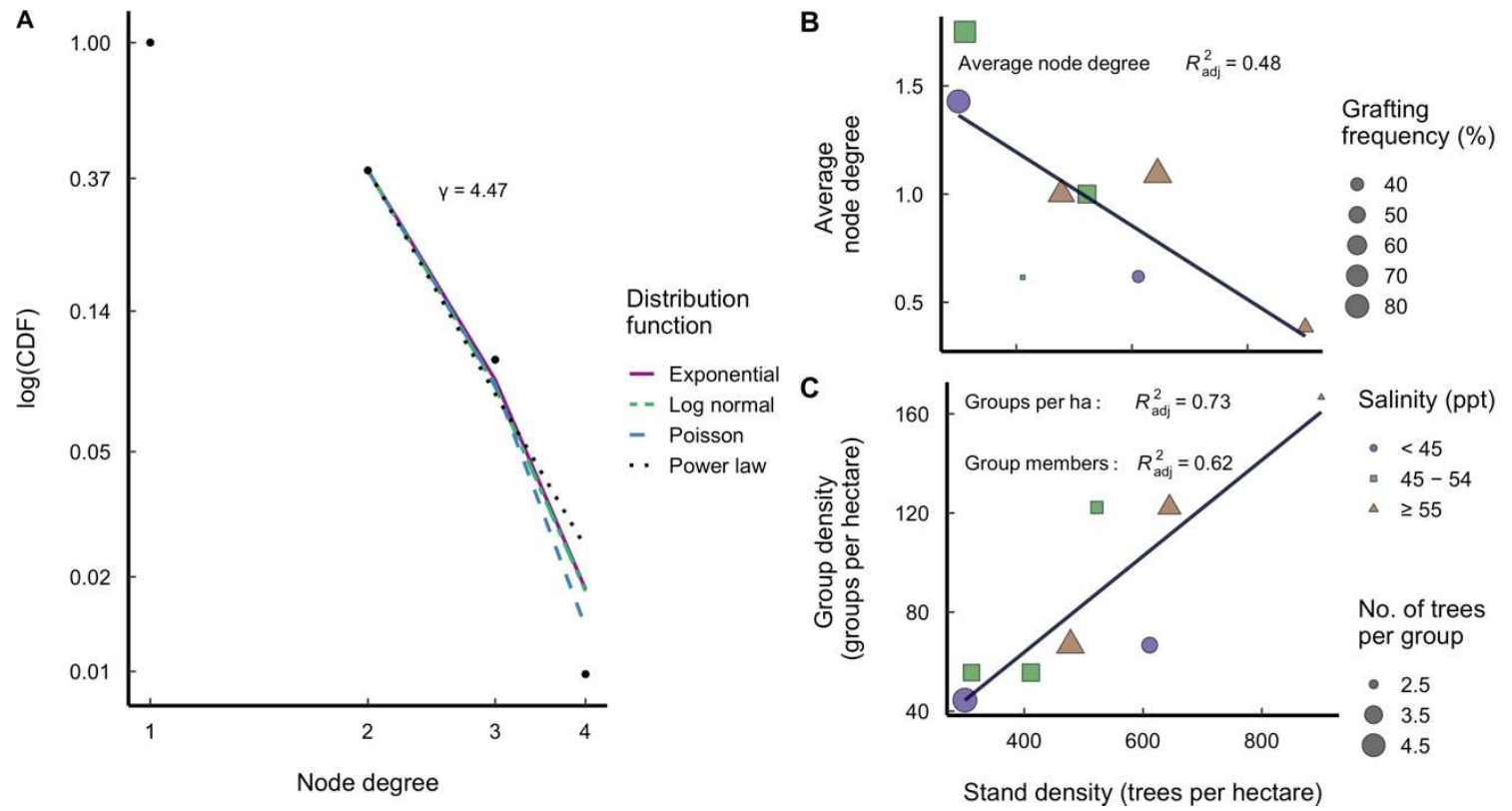


\section{METHODS}

\section{Study site}

The study site is located on the central coast of the Gulf of Mexico (GoM) at the La Mancha lagoon (Fig. 1A) at $19^{\circ} 33^{\prime}-19^{\circ} 36^{\prime} \mathrm{N} ; 96^{\circ} 22^{\prime}-96^{\circ} 24^{\prime} \mathrm{W}^{46}$. The surface of the lagoon's waterbody covers 135 ha and is surrounded by 300 ha of mangrove forest ${ }^{47}$. Annual precipitation in the area ranges between 1,200 and 1,500 $\mathrm{mm}$, and the annual mean temperature is $25^{\circ} \mathrm{C}^{48}$. Freshwater and marine water inputs into the lagoon come from extreme opposite directions: the connection to the GoM is located in the northern extreme, while a main riverine input is located in the southern extreme. This creates a year-round salinity gradient that increases northward, regardless of seasonality $25,49,50$. This is also reflected in the zonation of the mangrove species, where the northern and most saline environments are mainly represented by Avicennia germinans with minor Rhizophora mangle, which gradually pass into mixed stands co-dominated by $R$. mangle and $A$. germinans or A. germinans and Laguncularia racemosa towards the southern end of the $\operatorname{lagoon}^{49,51}$.

Within this mangrove forest, $30 \times 30$ m permanent plots established in 2010 are arranged along the salinity gradient. They are all oriented to true north and located equidistant from the main water body. The seven plots selected for this study are located at increasing distances from the lagoon's inlet to the GoM (between 500 and 3,000 m) to capture the salinity gradient along the lagoon. A new plot within the highest salinity range was established in 2017 to include a site with a stand density similar to other sites but with contrasting salinity. For the pre-established plots, existing tree parameters were recovered from a publicly available database ${ }^{52}$, including a unique ID, species, $x$ - and $y$-axis positions in the plot, stem diameter at $130 \mathrm{~cm}$ from the soil surface $\left(D_{130}\right)$ and height $(H)$. For the newly established 
plot, the same tree parameters were measured using a laser rangefinder (Laser Rangefinder Forestry Pro 550; Nikon Vision Co., Ltd, Tokyo, Japan), and tree positions were determined using a compass and the rangefinder following standard forestry procedures ${ }^{53}$.

For each plot, during April and September 2017, two pseudo-replicate pore water samples were collected from each corner and the middle of the plots from $20 \mathrm{~cm}$ below the ground surface using a custom-made pore water extractor ${ }^{54}$ and immediately analysed for $\mathrm{pH}$, salinity, temperature and redox potential (Ultrameter II; Myron L Company) $)^{55}$.

\section{Root graft data collection}

A non-destructive method was used to detect the potential location of root grafts using a portable Doppler ultrasound probe (DU; SonoTrax Basic; Edan Instruments GmbH, Hessen, Germany) and a set of steel rods. The mangrove roots were gently located with steel rods with the DU probe placed on the tree stem. Following an adapted method originally developed to measure the woody root extensions of $A$. germinans ${ }^{37}$, the probe was then gradually moved from the stem to the consecutive rods in contact with the target root. Each tree was examined following the consecutive order of the tree tag numbers within the plots by assessing their grafting to all immediate neighbours.

Placing the DU on a tree stem collar ring, a steel rod was used to probe the soil to shallow depths, and an amplitude monitor indicated when a root belonging to the stem was touched. Leaving this first steel rod in contact with the root, a second rod was used to further probe close to the first rod in the assumed direction of the course of the root until another positive signal was obtained. The interchangeable waterproof probe of the DU was then attached to the second steel rod, having been proofed to be in contact with the initial root, and the 
process repeated until either the root was too deep or too thin to be followed or led to another tree. In the latter case, the probe was held on the second tree stem and the last verified steel rod was used to again probe until another positive signal was returned by the DU from the second stem. The DU-located root graft was then verified by localised excavation of each target tree's neighbour. Although we were unable to verify false negatives, we calculated a $6 \%$ probability of finding false-positive connections (i.e. 12 false positives out of 200 connections detected), all identified false-positives were treated as non-grafted trees. We did not have any means to evaluate false-negative rates.

Using this method, a total of 376 A. germinans tree-root systems were followed during April and May 2017. These were mapped and used to determine the grafted network topology: node degree (number of direct connections for each tree), number of groups of grafted trees and mean group size (number of individuals within a group).

To estimate the pressure each tree receives from its neighbours, an index of neighbourhood asymmetry was calculated as a function of the size and distance of all neighbouring trees $\left(\right.$ trees $\left._{j}\right)$ within a $5 \mathrm{~m}$ radius of the target tree (tre $e_{i}$; see Supplementary Information). A large index of neighbourhood asymmetry implies that the neighbours are large and in close proximity, potentially exerting higher competition pressure on a target tree than a small neighbourhood asymmetry would. The $5 \mathrm{~m}$ radius was chosen because it had been previously identified as the optimal radius for detecting the responses of trees to its neighbours at the same study site ${ }^{25}$. Neighbourhood asymmetry was only calculated for trees where their complete neighbourhood was within the limits of the sampling plots (187 trees) to avoid biased neighbourhood asymmetry sizes related to incomplete information for neighbouring trees located outside a plot. 


\section{Data analysis}

Both the density of the target species $A$. germinans and the total stand density (including Avicennia germinans, Rhizophora mangle and Laguncularia racemosa) were calculated as the number of trees per hectare. The replicate pore water salinity values for each sampling point were averaged, and the resulting five salinity values were used to estimate a mean plot salinity, including the standard error. The proportion of grafted trees at each plot was calculated as the number of $A$. germinans grafted trees divided by the total number of grafted A. germinans trees in the stand. The top-height trees at each stand (the $20 \%$ biggest) were selected as per stem diameter because it was measured in the field and is considered more accurate than tree height, which is estimated through stem diameter measurements ${ }^{53}$.

Logistic regression was implemented using a generalised mixed effects model to assess the probability of grafting as a function of stem diameter, total stand density and salinity. The model included site identity as a random effect and stem diameter, site salinity and total stand density as fixed effects after assessing the autocorrelation between response variables (Extended Data Fig. 2) and all intra- and cross-level interactions between stand density and salinity. All the variables were z-transformed using the mean and standard deviation of each variable across all sites.

To explore the effect of root grafting and neighbourhood pressure on tree allometry, in the generalised additive mixed effects model (GAMM), salinity and condition were included as fixed effects (cyclic cubic regression spline), neighbourhood asymmetry and stem diameters were included as smooth terms with smooth functions (Duchon spline) and the sampling plot was included as a random effect. The best model explaining tree height was selected using a minimal Akaike information criterion value following a stepwise removal of non-significant 
response variables $(\mathrm{N}=138$ single-stem $A$. germinans trees with a computed asymmetric neighbourhood).

In the existing database of tree parameters ${ }^{52}$, multiple-stem trees are recorded following the traditional convention of summing the diameters of each stem but by measuring only the height of the tallest stem ${ }^{35}$, leading to inaccurate diameter-height allometry. To avoid biased results when relating stem diameter to stem height and the probability of root grafting, multiple-stemmed trees (52 trees) were not included in the logistic regression, nor GAMM, (which also excluded trees that did not have their full neighbourhoods inside de plots), resulting in a final number of trees of 324 and 138 included in the logistic regression and GAMM, respectively.

\section{To further assess the implications of root grafting slenderness (an allometric trait that} modulates mechanical stability), a linear model was used to evaluate the variations in the slenderness coefficient on the 324 single-stem $A$. germinans trees. To normalize the data, we performed a square root transformation of both the slenderness index and stem diameter. The model included slenderness as response, and an interaction term between grafting condition stem diameter and neighbourhood asymmetry. The final model was plotted back transforming the $\mathrm{x}$ and $\mathrm{y}$ axis to the original values of stem diameter and slenderness for simplicity of figure presentation (Fig. 2C).

Network parameters (node degree, number of groups per hectare and group size) were used to assess random network formation by comparing the probability of networks having a scalefree power-law distribution with random process distributions (i.e. log-normal, exponential and Poisson). Scale-free networks do not occur randomly because a relative change in one 
node results in a proportional, relative change in another node. Scale-free power-law distributions indicate the continuous expansion of networks and preferential attachment, where new nodes are constantly added and previously well-connected nodes are more likely to acquire new connections ${ }^{11,56}$. We then related network node degree, group size and frequency (number of trees grafted within groups and frequency of groups per hectare, respectively) to stand density and site salinity using linear regressions. All 376 A. germinans trees, including multi-stemmed trees, were used for this analysis.

All the statistical analyses were conducted using $\mathrm{R}$ programming language ${ }^{57}$. Specifically, we used the $1 m e 4^{58}$, DHARMa ${ }^{59}$ and gamm $4{ }^{60}$ packages for the logistic regression and the GAMM construction and diagnosis. For the network analyses, we used igraph ${ }^{61}$ to estimate the node degrees and PoweRlaw ${ }^{62}$ to explore the distribution. All figures presented were developed using ggplot $2^{63}$.

\section{Data availability}

Data on allometric attributes of the trees (i.e. height, stem diameter and position in stand) are publicly available at https://doi. org/10.5525/gla.researchdata.657. Root Network formation and sediment salinity databases will be made publicly available from the research data repository of the University of Glasgow upon acceptance for publication. All other data supporting findings, including coding resources, are available from the corresponding author upon request.

\section{References}

46. López-Portillo, J. A., Ewers, F. W. \& Angeles, G. Sap salinity effects on xylem conductivity in two mangrove species. Plant Cell Environ. 28, 1285-1292 (2005).

47. RAMSAR. La Mancha y El Llano: Ramsar sites information service. (2004).

48. Gulfbase. Laguna La Mancha| GulfBase. (2017). 
49. Hernández, C. M. A., Zaragoza, C. G., Iriarte-Vivar, S., Flores-Verdugo, F. J. \& Casasola, P. M. Forest structure, productivity and species phenology of mangroves in the La Mancha lagoon in the Atlantic coast of Mexico. Wetl. Ecol. Manag. 19, 273$293(2011)$.

50. Méndez-Alonzo, R., Hernández-Trejo, H. \& López-Portillo, J. A. Salinity constrains size inequality and allometry in two contrasting mangrove habitats in the Gulf of Mexico. J. Trop. Ecol. 28, 171-179 (2012).

51. López-Portillo, J. A., Ezcurra, E., Lopez-Portillo, J. \& Ezcurra, E. Response of three mangroves to salinity in two Geoforms. Funct. Ecol. 3, 355-361 (1989).

52. Vovides, A. G., Berger, U. \& López-Portillo-Portillo, J. Data base of tree allometric parameters (2018). doi:https://doi. org/10.5525/gla.researchdata.657

53. Pretzsch, H. Forest dynamics growth and yield. From Measurement to Model 1, (Springer-Verlag, 2009).

54. McKee, K. L., Mendelssohn, I. A. \& Hester, M. W. Reexamination of pore water sulfide concentrations and redox potentials near the aerial roots of Rhizophora mangle and Avicennia germinans. Am. J. Bot. 75, 1352-1359 (1988).

55. Myron L Company. ULTRAMETER II ${ }^{\mathrm{TM}}$. Oper. Manual, Ver. Model. 6Pfc 4P (2011).

56. Barabási, A. L. Scale-free networks: A decade and beyond. Science. 325, 412-413 (2009).

57. R Core Team. R: A language and environment for statistical computing. R Foundation for Statistical Computing. (2019).

58. Bates, D., Mächler, M., Bolker, B. \& Walker, S. Fitting Linear Mixed-Effects Models using lme4. J. Stat. Softw. 67, 1-45 (2015).

59. Hartig, F. DHARMa: residual diagnostics for hierarchical (multi-level /mMixed) regression models. R package version 0.2.7. (2020). 
60. Wood, S. \& Scheipl, F. gamm4: Generalized additive mixed models using ' $m g c v$ ' and 'Ime4'. (2017).

61. Csardi, G. \& Nepusz, T. The igraph software package for complex network research. InterJournal Complex Sy, 1695 (2006).

62. Colin, S. G. Fitting Heavy Tailed Distributions: The poweRlaw Package. J. Stat. Softw. 64, 1-16(2015).

63. Wickham, H. ggplot2 Elegant Graphics for Data Analysis (Use R!). Springer (2016). doi:10.1007/978-0-387-98141-3 


\section{Figures}
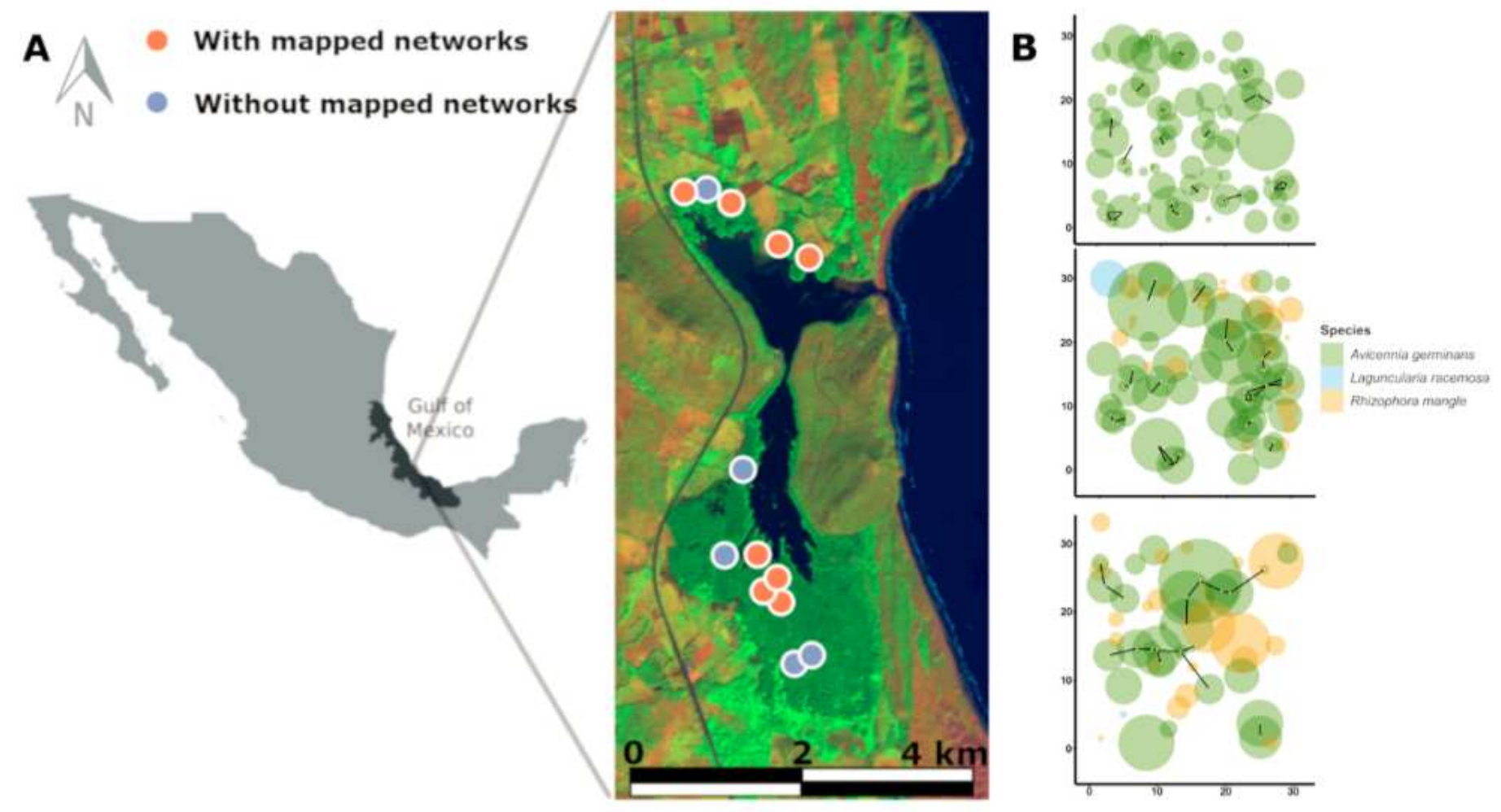

\section{Figure 1}

A Study site located on the central coast of the Gulf of Mexico (left). La Mancha lagoon (see insert), surrounded by mangrove vegetation, contains 13 permanent plots (red and blue points) used for vegetation monitoring. Root grafts were mapped within eight of these stands (red points). B Root-grafted tree network maps representative of sites with low, medium and high salinity and the stand density (left, middle and right, respectively). The yellow dots represent stem positions; the coloured circles (green, peach and blue) are the tree crowns of black mangrove (Avicennia germinans), red mangrove (Rhizophora mangle) and white mangrove (Laguncularia racemosa), respectively; and the black lines represent graft connections. Note: The designations employed and the presentation of the material on this map do not imply the expression of any opinion whatsoever on the part of Research Square concerning the legal status of any country, territory, city or area or of its authorities, or concerning the delimitation of its frontiers or boundaries. This map has been provided by the authors. 


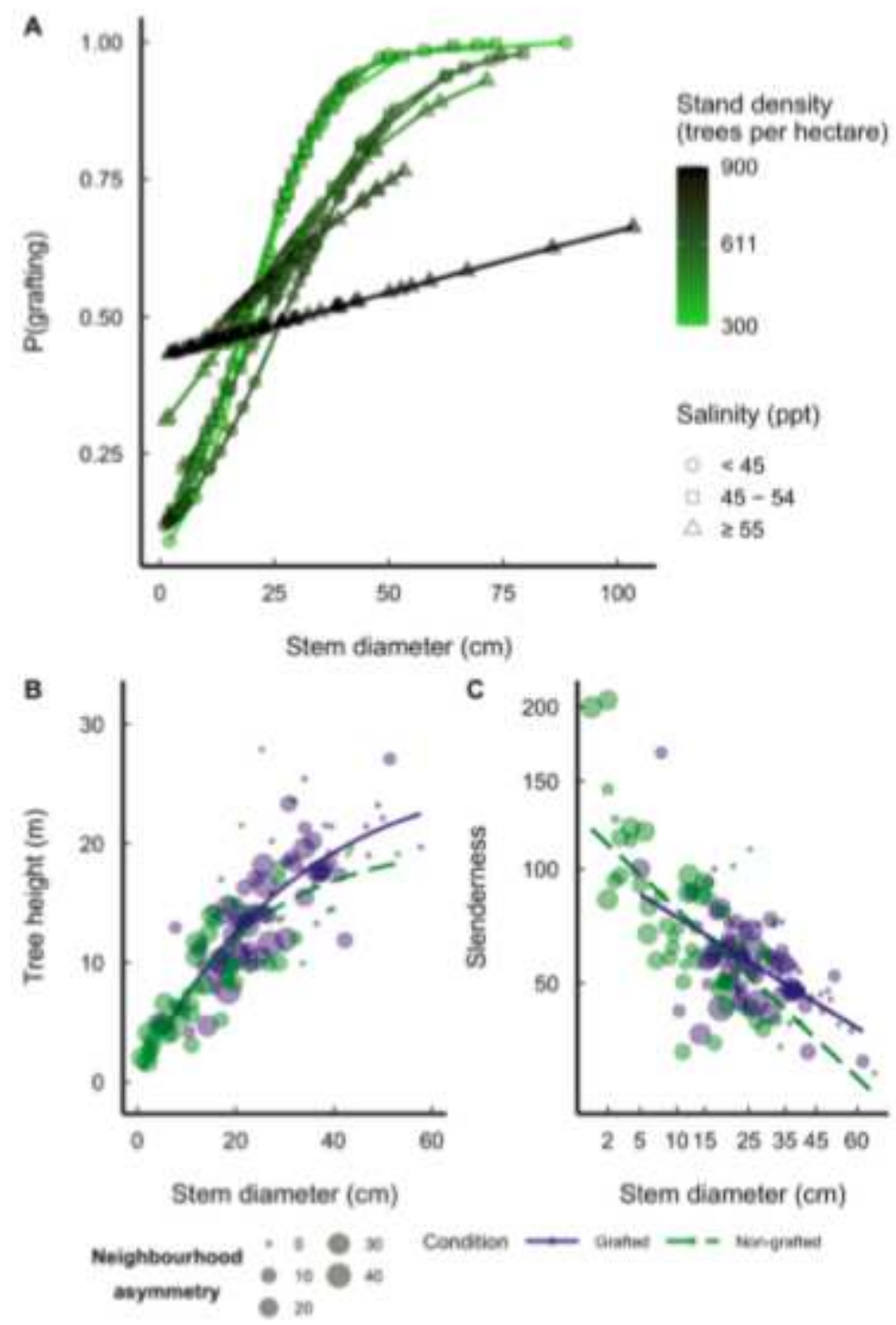

Figure 2

A Logistic regression testing of the main drivers of root grafting. Although, for all cases, the probability of grafting increases with increasing stem diameter, at higher salinity stress and total density values, trees graft at smaller stem diameters, and the probability curve rises earlier and is steeper. B Non-linear relationship between stem diameter and tree height showcasing stem diameter-height allometric curves that are steeper for grafted (purple) trees compared with non-grafted (green) trees. There is a predominance of grafted trees with stem diameters $>20 \mathrm{~cm}$, whereas the tallest trees are either grafted or have smaller values of neighbourhood asymmetry (circle size). C Sharp decrease in slenderness coefficient with increasing stem diameter for non-grafted trees, at higher stem diameters grafted trees are more slender 

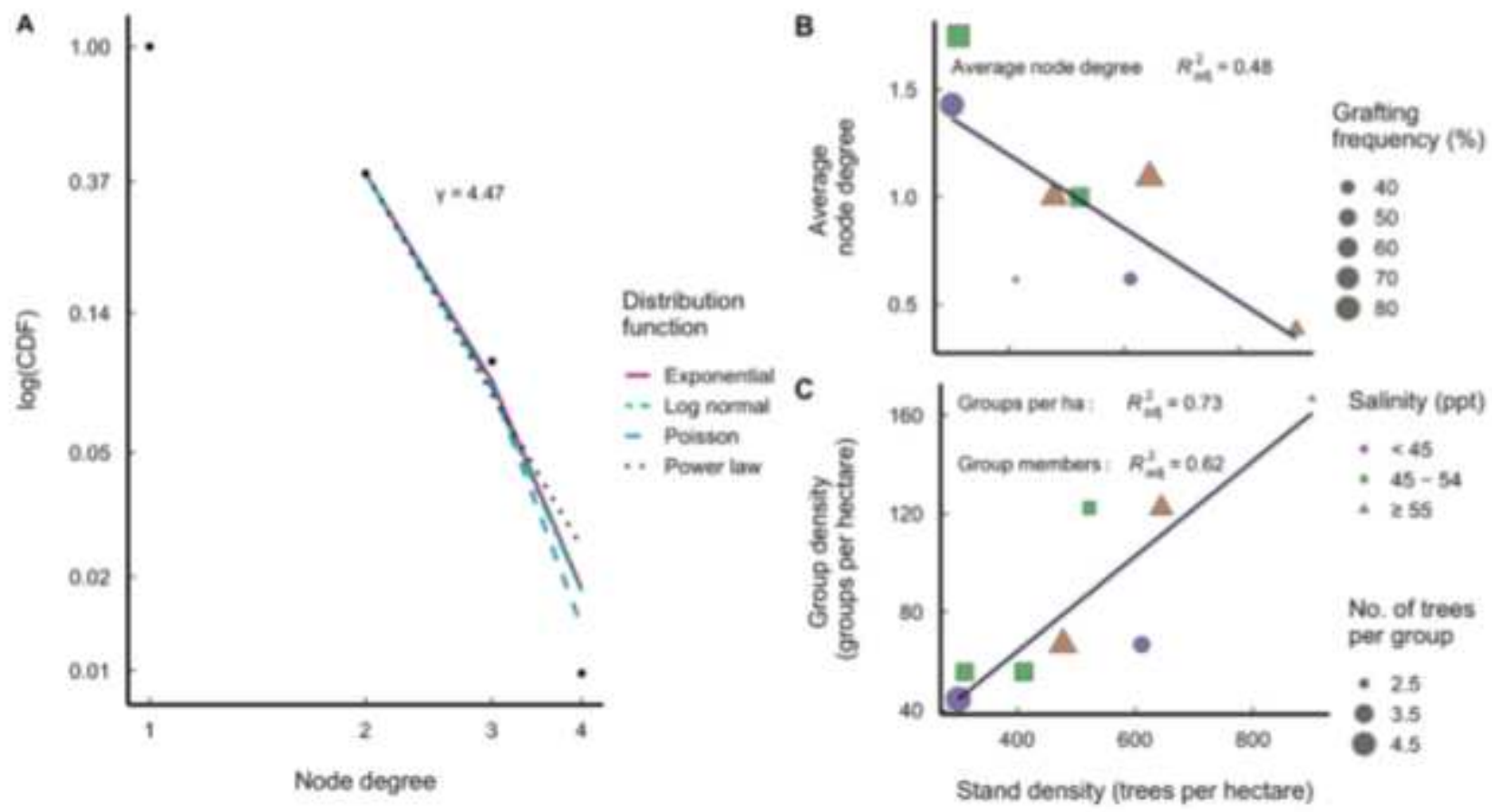

\section{Figure 3}

A Comparison of log-transformed cumulative distribution functions (CDF). The number of direct connections for a given tree (node degree) shows that although the root graft networks might fit a scalefree power-law distribution, Poisson, log-normal and exponential distributions cannot be discarded. B Linear regression showing a reduction on the average node degree of the networks along the $A$. germinans stand-density gradient and grafting frequency (\%). Shape and colour depict the salinity range of the plots (purple circles $>45 \mathrm{ppt}$, green squares $45-55 \mathrm{ppt}$ and brown triangles $>55 \mathrm{ppt}$ ) and the size of each shape indicates the stand's grafting frequency. $C$ Linear regression showing an increasing number of groups of grafted trees per hectare with significant reduction in mean group size.

\section{Supplementary Files}

This is a list of supplementary files associated with this preprint. Click to download.

- RCSupplementaryInformation.pdf 